\title{
Normal Striatal Vesicular Acetylcholine Transporter Expression in Tourette Syndrome
}

\author{
(1) Roger L. Albin, ${ }^{1,2,3}$ Christine Minderovic, ${ }^{4}$ and Robert A. Koeppe ${ }^{3,4}$
}

DOI:http://dx.doi.org/10.1523/ENEURO.0178-17.2017

${ }^{1}$ Neurology Service and Geriatrics Research, Education, and Clinical Center, Veterans Affairs Ann Arbor Health System, Ann Arbor, Ml 48105, ${ }^{2}$ Department of Neurology, University of Michigan, Ann Arbor, MI 48109, ${ }^{3}$ University of Michigan Morris K. Udall Center, Ann Arbor, MI 41809, and ${ }^{4}$ Department of Radiology, University of Michigan, Ann Arbor, MI 48109

\begin{abstract}
Considerable prior work suggests basal ganglia dysfunction in Tourette syndrome (TS). Analysis of a small number of postmortem specimens suggests deficits of some striatal interneuron populations, including striatal cholinergic interneurons. To assess the integrity of striatal cholinergic interneurons in TS, we used $\left[{ }^{18} \mathrm{~F}\right] \mathrm{FEOBV}$ positron emission tomography (PET) to quantify striatal vesicular acetylcholine transporter (VAChT) expression, a measure of cholinergic terminal density, in human TS and control subjects. We found no evidence of striatal cholinergic deficits. Discrepant imaging and postmortem analysis results may reflect agonal or postmortem changes, medication effects, or significant disease heterogeneity.
\end{abstract}

Key words: Acetylcholine; Striatum; Tourette Syndrome; VChAT

\section{Significance Statement}

Prior postmortem analyses suggest loss of striatal cholinergic interneurons in Tourette syndrome (TS). We evaluated this possibility with $\left[^{18} \mathrm{~F}\right] \mathrm{FEOBV}$ positron emission tomography (PET), a ligand for the vesicular acetylcholine transporter (VAChT) and measure of cholinergic terminal integrity. We studied TS and matched control subjects. There were no differences between TS and control subjects in striatal $\left[{ }^{18} \mathrm{~F}\right] \mathrm{FEOBV}$ binding, consistent with intact striatal cholinergic neurons in TS.

\section{Introduction}

Tourette syndrome (TS) is a common neurodevelopmental disorder characterized by motor and phonic tics (Robertson, 2012). TS is associated often with comorbid behavioral problems, notably obsessive-compulsive behaviors, and attention deficit-hyperactivity disorder. Considerable evidence points to basal ganglia dysfunction in TS (Albin and Mink, 2006; Ganos et al., 2013). Striatal dysfunction is suggested by response of tics to dopamine

Received May 19, 2017; accepted July 10, 2017; First published July 27, 2017. The authors declare no competing financial interests.

Author contributions: R.L.A. and R.A.K. designed research; R.L.A. and C.M. performed research; R.L.A. and R.A.K. analyzed data; R.L.A. and R.A.K. wrote the paper.

This work was supported by the National Institutes of Health-National Institute of Neurological Disorders and Stroke Grant R21 NSNS088302.

Acknowledgements: We thank the anonymous reviewers for helpful comments. antagonists and the presence of tics in other disorders, such as Huntington disease, with unequivocal striatal pathology. Tics are often conceptualized as disordered habits, and habit formation and maintenance are thought to be primary functions of basal ganglia circuits (Yin and Knowlton, 2006; Delorme et al., 2016). Accumulated structural and functional imaging evidence strongly supports the concept of basal ganglia, and particularly striatal, dysfunction in TS (Ganos et al., 2013).

Correspondence should be addressed to Roger L. Albin, MD, Dept. of Neurology, University of Michigan, 5023 BSRB, 109 Zina Pitcher Place, Ann Arbor, MI 48109-2200, E-mail: ralbin@umich.edu.

DOI:http://dx.doi.org/10.1523/ENEURO.0178-17.2017

Copyright (C) 2017 Albin et al.

This is an open-access article distributed under the terms of the Creative Commons Attribution 4.0 International license, which permits unrestricted use, distribution and reproduction in any medium provided that the original work is properly attributed. 
Pathologic evidence of basal ganglia and striatal abnormalities, however, is sparse, as only a small number of postmortem specimens have been analyzed. Vaccarino and colleagues reported several findings in anatomic analyses of a small number $(N=5)$ of postmortem TS specimens (Kalanithi et al., 2005; Kataoka et al., 2010). This group reported diminished striatal parvalbuminimmunoreactive interneurons (probable fast spiking interneurons) and dorsal striatal cholinergic interneurons. In addition, this group reported abnormal distribution of pallidal parvalbumin-immunoreactive neurons (probable GABAergic projection neurons), suggesting abnormal neuronal migration in TS. Subsequent transcriptomic analysis of a larger set $(N=9)$ of postmortem TS striata also suggested diminished striatal cholinergic interneurons (Lennington et al., 2016).

The reported deficit of dorsal striatal cholinergic interneurons is substantial, $\sim 50 \%$, and diminished cholinergic signaling is a plausible contributor to TS pathophysiology. While only a small fraction $(\sim 1 \%)$ of striatal neurons, cholinergic interneurons ramify widely within the striatum and play important roles in modulating striatal functions (Deffains and Bergman, 2015). Xu et al. (2015) reported that mice with selective depletion of dorsolateral striatal interneurons exhibited motor behaviors analogous to tics.

New molecular imaging methods allow quantification of striatal cholinergic terminals in vivo. $\left[{ }^{18} \mathrm{~F}\right] \mathrm{FEOBV}$ is a ligand for the vesicular acetylcholine transporter (VAChT), the protein responsible for pumping acetylcholine into synaptic vesicles. VAChT is uniquely expressed by cholinergic neurons and $\left[{ }^{18} \mathrm{~F}\right] \mathrm{FEOBV}$ positron emission tomography (PET) effectively cholinergic delineates projection systems in vivo (Petrou et al., 2014). To determine if the postmortem results reported previously reflect the integrity of striatal cholinergic interneurons in TS, we used $\left[{ }^{18} \mathrm{~F}\right] \mathrm{FEOBV}$ PET to measure striatal cholinergic terminal density in TS and control subjects.

\section{Materials and Methods}

\section{Subjects and subject characterization}

This study was approved by the University of Michigan Medical School Institutional Review Board. TS and control subjects between the ages of 18 and 46 were recruited for study participation. Informed consent was obtained from all subjects. TS was defined using conventional DSM criteria. Exclusion criteria included history of substance abuse, history of neurologic disease (other than TS) and for control subjects, history of significant psychiatric disease. Potential subjects using medications that might interact with cholinergic neurotransmission were excluded. All subjects underwent a standard evaluation including recording of demographic information, medical history, concomitant medications, history of TS, general physical and neurologic examination, the Yale Global Tourette Severity Scale (YGTSS), the Yale-Brown Obsessive Compulsive Scale (YOBCS), and the Connors' Adult ADHD Rating Scale (self-administered short form, CAARS-S:S). All subjects had normal neurologic examinations (other than presence of tics) on the days of evaluations. We studied 18 men and 4 women.

\section{PET methods}

$\left[{ }^{18} \mathrm{~F}\right] \mathrm{FEOBV}$ was prepared as described previously (Shao et al., 2011; Petrou et al., 2014). [ ${ }^{18}$ F]FEOBV (288$318 \mathrm{MBq}$ ) was administered via intravenous bolus. Subjects were scanned on an ECAT Exact HR+ PET tomograph (Siemens Molecular Imaging). Brain imaging was conducted in three imaging periods. The first period began at injection and continued for $90 \mathrm{~min}$. The subjects were then given a 30-min break, followed by a second imaging period from 120-150 min, an additional break, and then a third imaging period from 180-210 min. Dynamic PET scans were reconstructed using Fourier rebinning (FORE) and the iterative 2D-OSEM algorithm, with four iterations, 16 subsets, and no postreconstruction smoothing. The entire dynamic sequence was coregistered to the final form of the first 90-min scanning period.

The primary analysis was performed using the average of the coregistered 120- to 150- and 180- to 210-min scan periods (termed "late static"). FreeSurfer was used on each individual's T1-weighted MR to define gray matter and white matter voxels. The entire coregistered PET sequence was registered to the MR. The segmented white matter mask from FreeSurfer ( 1 for WM; 0 elsewhere) was smoothed to PET resolution, and then a threshold of 0.90 applied to the mask, yielding a volume of interest where the partial volume contribution from non-white matter regions to the mask was $<10 \%$ for every voxel. This white matter volume-of-interest was then applied to the PET data and used as a normalizing (intensity scaling) factor for the late static scan.

Besides the standard static analysis, we applied two different compartmental kinetic modeling techniques to the entire dynamic sequence, one using metabolite-corrected arterial blood sampling and a full two-tissue compartment model, and a second using reference tissue model with subcortical white matter as the reference tissue (Logan et al., 1996). The results using all three approaches were yielded very similar results and the same conclusions, so only the late static scan analysis is presented.

Right and left caudate and putamen $\left[{ }^{18} \mathrm{~F}\right] \mathrm{FEOBV}$ binding values were averaged to produce to produce single caudate and putaminal values for each subject.

MRI methods: MRI imaging was performed on a 3 Tesla Philips Ingenia System (Philips) using a 15-channel head coil. A standard T1 weighted series of a 3D inversion recovery prepared turbo-field echo was performed in the sagittal plane using TR/TE/TI $=9.8 / 4.6 / 1041 \mathrm{~ms}$; turbo factor $=200$; single average; FOV $=240 \times 200 \times 160$ $\mathrm{mm}$; acquired matrix $=240 \times 200$. One hundred and sixty slices were reconstructed to $1-\mathrm{mm}$ isotropic resolution. Cortical and Subcortical segmentation was performed with FreeSurfer version 5 (freesurfer-i686-apple-darwin9.8. 0-stable5-20110525; https://surfer.nmr.mgh.harvard.edu/ fswiki/FreeSurferMethodsCitation), developed by the Laboratory for Computational Neuroimaging at the Athinoula A. Martinos Center for Biomedical Imaging. The programs were run in the fully automated mode. Volumes for all standard FreeSurfer volumes were obtained. 
Table 1. Clinical characteristics of subjects

\begin{tabular}{|c|c|c|c|c|c|c|}
\hline & Age & $\begin{array}{c}\text { Family } \\
\text { History of } \\
\text { TS or Tics }\end{array}$ & $\begin{array}{l}\text { Global } \\
\text { YGTSS }\end{array}$ & YBOCS & $\begin{array}{l}\text { CAARS-S } \\
\text { ADHD } \\
\text { Index }\end{array}$ & $\begin{array}{r}\text { Medications } \\
\text { (Subject N) }\end{array}$ \\
\hline $\begin{array}{c}\text { TS } \\
N=12\end{array}$ & $\begin{array}{c}\text { Mean } 26.1 \\
\text { years } \\
(\text { SD } 8.25 \\
\text { Range19-44) }\end{array}$ & $4 / 12$ & $\begin{array}{c}\text { Mean 36 } \\
\text { (SD 14.1; } \\
\text { Range7-54) }\end{array}$ & $\begin{array}{c}\text { Mean 11.6 } \\
\text { (SD 6.0; } \\
\text { Range 2-18) }\end{array}$ & \begin{tabular}{|c|}
49.3 \\
$(S D ~ 10.4 ;$ \\
Range 34-71)
\end{tabular} & $\begin{array}{c}\text { Lithium(1) } \\
\text { Tetrabenazine (1) } \\
\text { Haloperidol (1) } \\
\text { Diazepam (1) } \\
\text { Clonidine (1) } \\
\text { Topirimate (1) }\end{array}$ \\
\hline $\begin{array}{l}\text { Control } \\
\qquad N=10\end{array}$ & $\begin{array}{c}\text { Mean 23.8 } \\
\text { years } \\
\text { (SD 3.22; } \\
\text { Range19-31) }\end{array}$ & $0 / 10$ & $N A^{3}$ & $\begin{array}{c}\text { Mean 0.3 } \\
\text { (SD 0.9; } \\
\text { Range 0-3) }\end{array}$ & \begin{tabular}{|c|}
41.4 \\
(SD 7.8; \\
Range 31-55)
\end{tabular} & None \\
\hline
\end{tabular}

\footnotetext{
1 TS not different from NC; $p=0.42$; two-tailed $t$ test.

2 Possible or definite TS/Tics.

${ }^{3}$ Not applicable.

${ }^{4}$ TS different from NC; $p<0.0001$; nondirectional Mann-Whitney $U$ test.

${ }^{5}$ TS different from NC; $p<0.05$; nondirectional Mann-Whitney $U$ test.
}

\section{Statistical analysis}

Striatal $\left[{ }^{18} \mathrm{~F}\right.$ FEOBV binding in TS and NC subjects was compared with two-tailed $t$ tests without correction for multiple comparisons. Ages of TS and NC subjects were compared with a two-tailed $t$ test. Striatal volumes were compared with two-tailed $t$ tests. YBOCS and CAARS-S:S results in TS and NC subjects were compared with non-directional MannWhitney $U$ tests. Potential correlation between global YGTSS scores and striatal $\left[{ }^{18} \mathrm{~F}\right] \mathrm{FEOBV}$ binding were assessed with Pearson product moment correlation analysis.

\section{Results}

\section{Subject characteristics}

We studied 12 TS subjects ( 2 women:10 men) and 10 control subjects (2 women:8 men). Clinical Characteristics are presented in Table 1.

\section{PET results}

There was no difference in striatal $\left[{ }^{18} \mathrm{~F}\right] \mathrm{FEOBV}$ binding between TS and NC subjects (Fig. 1; Table 2). Nor was there any difference between TS and NC subjects in any other brain region (data not shown). There was nothing resembling a trend in differences of $\left[{ }^{18} \mathrm{~F}\right] \mathrm{FEOBV}$ binding between TS and NC subjects in any region. In TS subjects, there was no correlation between striatal $\left[{ }^{18} \mathrm{~F}\right] \mathrm{FEOBV}$ binding and global YGTSS scores: caudate, $r^{2}=0.002(p=$ $0.88)$; putamen, $r^{2}=0.00(p=0.98)$.

\section{MRI results}

We assessed striatal volumes to exclude differences in striatal volumes between TS and control subjects as a confounding variable. There were no differences in caudate $(p=0.282)$ or putamen $(p=0.38)$ volumes between TS and controls subjects. TS mean caudate volume was $3895 \mathrm{~mm}^{3}$ (SD 781) and TS mean putamen volume was $6315 \mathrm{~mm}^{3}$ (SD 905). Control mean caudate volume was $4124 \mathrm{~mm}^{3}$ (SD 719) and control mean putamen volume was $6422 \mathrm{~mm}^{3}$ (SD 713).

\section{Discussion}

Our results do not indicate any striatal cholinergic neuron deficit in TS. Our results do not even suggest any trend toward diminished striatal cholinergic terminals or, indeed, altered cholinergic projections in any brain region. These results differ markedly from those obtained in postmortem studies.

$\left[{ }^{18} \mathrm{~F}\right] \mathrm{FEOBV}$ is a highly specific ligand for VAChT, the protein responsible for pumping acetylcholine into synaptic vesicles. VAChT is expressed at uniquely high levels by cholinergic neurons and concentrated in cholinergic terminal synaptic vesicles. $\left[{ }^{18} \mathrm{~F}\right] \mathrm{FEOBV}$ binding appears to be a sensitive measure of cholinergic terminal integrity. In preclinical experiments, Parent et al. $(2012,2013)$ demonstrated that $\left[{ }^{18} \mathrm{~F}\right] \mathrm{FEOBV}$ PET imaging in rats detected modest $(\sim 20 \%)$ changes in cortical cholinergic terminal density following basal forebrain lesions and smaller $(\sim 10 \%)$ changes in hippocampal cholinergic innervation accompanying aging. While striatal cholinergic interneurons comprise only a small fraction $(\sim 1 \%)$ of striatal neurons, they appear to have particularly luxurious axonal arbors. The expression of cholinergic neuron markers are higher in striatum than any other CNS region. This includes markers associated with cholinergic synapses and terminals such as acetylcholinesterase, VAChT, and the high affinity choline transporter (Vickroy et al., 1985). Cholinergic interneurons were historically thought to be the sole source of striatal cholinergic terminals. Using sensitive viral based tract tracing methods, Dautan et al. (2014) demonstrated that cholinergic pedunculopontine nucleus (PPN) complex neurons innervate the striatum. Prior work and their data suggest that pedunculopontine complex afferents make a relatively minor contribution to striatal 


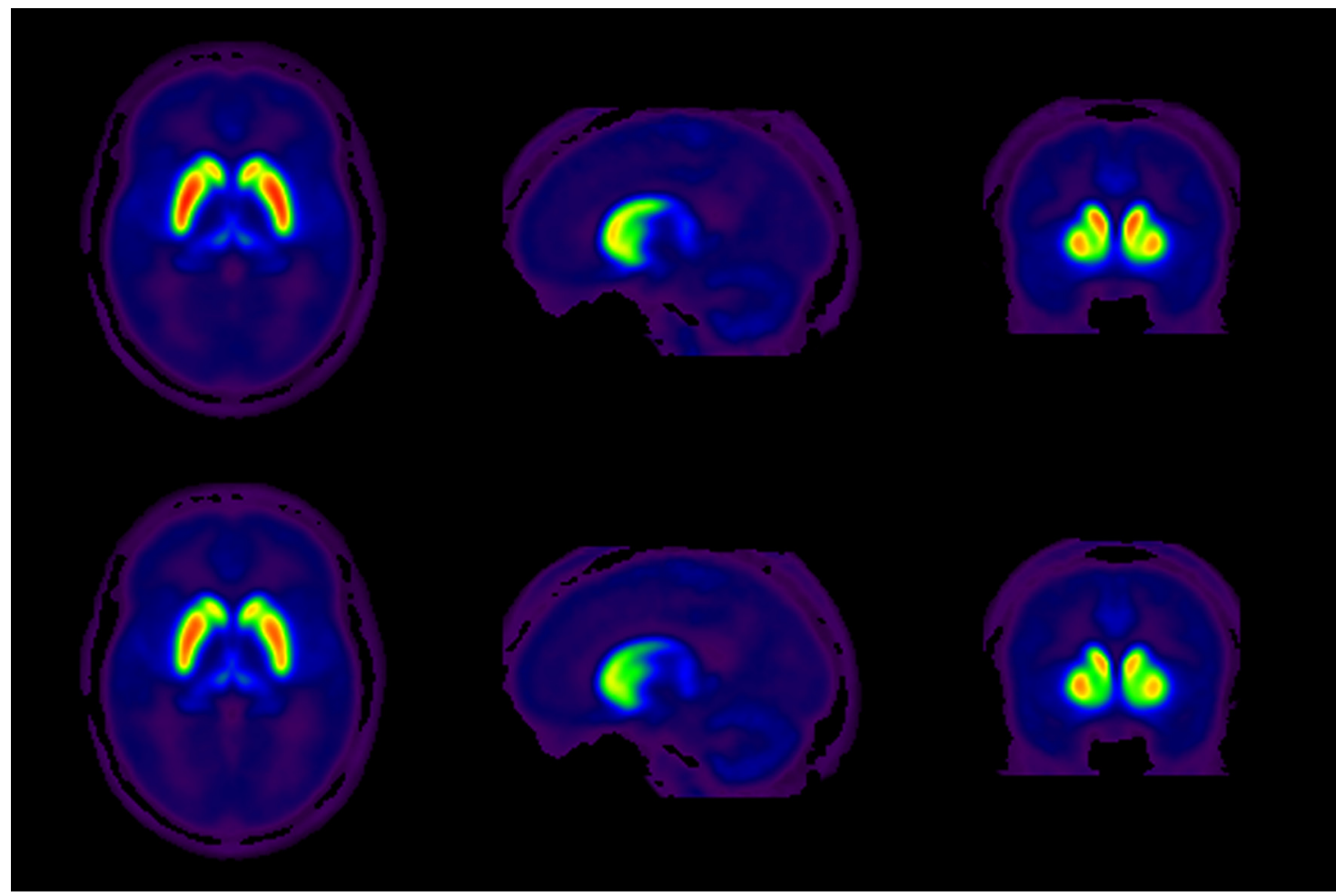

Figure 1. Striatal cholinergic terminal density measured by $\left[{ }^{18} \mathrm{~F}\right] \mathrm{FEOBV}$ PET in control (top row) and TS (bottom row) subjects. Averaged images from all subjects and images thresholded to optimize visualization of striatal $\left[{ }^{18} \mathrm{~F}\right] \mathrm{FEOBV}$ binding. No difference in striatal $\left[{ }^{18} \mathrm{~F}\right] \mathrm{FEOBV}$ binding between TS and NC subjects.

cholinergic terminal density. It is possible, although unlikely, that an increase in PPN cholinergic afferent terminals could mask loss of striatal cholinergic interneurons. Striatal PPN cholinergic afferents, however, are collaterals of PPN neurons projecting to other regions such as the thalamus and substantia nigra. We found no evidence of increased cholinergic terminals in any brain region.

There are three major possibilities for the discrepancy between our results and the prior postmortem findings. One possibility is that the apparent deficit of striatal cholinergic interneurons described previously is an artifact secondary to agonal states and/or postmortem changes inevitable in postmortem human tissues. Kataoka et al. (2010) assessed striatal cholinergic interneuron density in TS and control subjects with two complementary probes. They measured the density of choline acetytransferase (CAT)-immunoreactive and large (24- to 42- $\mu \mathrm{m}$ soma diameter) calretinin-immunoreactive striatal neuron perikarya. It is possible that the expression of these proteins

Table 2. Striatal $\left[{ }^{18} \mathrm{~F}\right] \mathrm{FEOBV}$ binding in TS and normal control subjects

\begin{tabular}{lcc}
\hline & Mean caudate & Mean putamen \\
& BP $($ SD $)$ & BP $(\mathrm{SD})$ \\
TS $(N=12)$ & $8.1016(2.4500)$ & $9.2805(2.7901)$ \\
Normal control $(N=10)$ & $7.8982(0.9475)$ & $9.1135(1.0031)$ \\
TS \% difference from control & $102.6 \%$ & $101.8 \%$ \\
$p^{1}$ & 0.3974 & 0.4248 \\
\hline
\end{tabular}

\footnotetext{
${ }^{1}$ Two-tailed $t$ test.
}

and/or their mRNAs is affected by agonal status. It is possible also that these proteins are degraded significantly after death. In the samples studied by Kataoka et al. (2010), there was a significant difference in postmortem interval between death and harvesting of TS and control tissues (TS, mean $22.6 \mathrm{~h}$, range 11-30 h; control, mean $14.1 \mathrm{~h}$, range $8.5-21 \mathrm{~h} ; p<0.0375$, directional Mann-Whitney $U$ test). Older biochemical literature on postmortem effects on brain CAT activity report varying results with some human and animal model studies describing modest postmortem effects on CAT activity and others describing significant declines in CAT activity with longer intervals between death and tissue freezing (Bowen et al., 1976; Fahn and Côté, 1976; Spokes and Koch, 1978; Spokes, 1979). Agonal state is known to differentially affect gene expression and may be important in this situation (Li et al., 2004). Spokes (1979), however, reported little effect of agonal state (sudden death versus prolonged illness) in humans on brain CAT activity.

Another possible reason for the discrepancy between our results and prior postmortem studies is medication effects. The subjects used in the study of Kataoka et al. (2010) are described as having severe TS and all were prescribed dopamine antagonist medications at the time of death. Some prior literature indicates that chronic dopamine antagonist administration in rodents reduces CAT activity and immunohistochemical detection of striatal cholinergic interneurons (Pedata et al., 1980; Mahadik et al., 1988; Terry et al., 2003; Kelley and Roberts, 2004). Only 1 of our TS subjects was using dopamine antago- 
nists at the time of study. Whether dopamine antagonists affect the expression of calretinin in striatal neurons is unknown. It is possible that medication effects and any postmortem effects could have additive effects on identification of cholinergic striatal neurons.

A final possible explanation for discrepant imaging and postmortem results is disease heterogeneity. Tics are the defining feature of TS and it is plausible that like some other neurologic phenomena, tics could result from dysfunction in more than one region. The subjects used in the studies of Kalanithi et al. (2005), Kataoka et al. (2010), and Lennington et al. (2016) were selected partially on the basis of severe TS. Our subjects generally had milder phenotypes (Table 1). It is possible that a striatal cholinergic deficit could be associated with severity of tic expression and be characteristic of a subpopulation of TS subjects.

An unlikely cause of discrepant results would be dissociation between VAChT and CAT expression. Expression of these proteins is usually coordinated as VAChT by encoded within the first intron of the CAT gene. Differential processing or degradation of VAChT and CAT transcripts is possible but in their study of striatal transcriptomic changes in TS, Lennington et al. (2016) reported both diminished CAT and VAChT transcript expression, which is more consistent with agonal/postmortem and/or medication effect as causes of discrepant imaging and postmortem analysis results.

Our results have implications for efforts to model TS. Xu et al. (2015) reported that selective depletion of murine dorsolateral striatal cholinergic interneurons resulted in increased stress- and amphetamine-induced stereotypies. Martos et al. (2017) recently described a murine model with selective deletion of all dorsal striatal cholinergic interneurons, reporting compulsive social behaviors. Rapanelli et al. (2017) reported that joint depletion of dorsal striatal cholinergic and parvalbumin-immunoreactive interneurons produced increased stereotyped behaviors and social interaction deficits in male, but not female, mice. Our results are most consistent with preservation of striatal cholinergic integrity in TS and suggest that these murine models, and possibly, these rodent measures of motor and social dysfunction, are not relevant to TS.

While we do not find evidence of striatal cholinergic interneuron depletion in TS, cholinergic interneurons play a critical role in striatal function and striatal cholinergic signaling is a plausible target for pharmacologic intervention in all disorders with striatal dysfunction (Deffains and Bergman, 2015). Small clinical series and case reports suggest beneficial effects of cholinesterase inhibitors in TS (Niederhofer, 2006; Cubo et al., 2008). Given the risks of dopamine antagonist treatments, pharmacologic manipulation of striatal cholinergic neurotransmission is still a viable clinical research avenue in TS.

\section{References}

Albin RL, Mink JW (2006) Recent advances in Tourette syndrome research. Trends Neurosci 29:175-182. CrossRef Medline

Bowen DM, Smith CB, White P, Davison AN (1976) Neurotransmitterrelated enzymes and indices of hypoxia in senile dementia and other abiotrophies. Brain 99:459-496. Medline
Cubo E, Fernández Jaén A, Moreno C, Anaya B, González M, Kompoliti K (2008) Donepezil use in children and adolescents with tics and attention-deficit/hyperactivity disorder: an 18-week, single-center, dose-escalating, prospective, open-label study. Clin Ther 30:182-189. CrossRef

Dautan D, Huerta-Ocampo I, Witten IB, Deisseroth K, Bolam JP, Gerdjikov T, Mena-Segovia J (2014) A major external source of cholinergic innervation of the striatum and nucleus accumbens originates in the brainstem. J Neurosci 34:4509-4518. CrossRef

Deffains M, Bergman H (2015) Striatal cholinergic interneurons and cortico-striatal synaptic plasticity in health and disease. Mov Disord 30:1014-1025. CrossRef Medline

Delorme C, Salvador A, Valabrègue R, Roze E, Palminteri S, Vidailhet M, de Wit S, Robbins T, Hartmann A, Worbe Y (2016) Enhanced habit formation in Gilles de la Tourette syndrome. Brain 139:605615. CrossRef Medline

Fahn S, Côté LJ (1976) Stability of enzymes in post-mortem rat brain. J Neurochem 26:1039-1042. [PMC] [5578]

Ganos C, Roessner V, Münchau A (2013) The functional anatomy of Gilles de la Tourette syndrome. Neurosci Biobehav Rev 37:10501062. CrossRef Medline

Kalanithi PS, Zheng W, Kataoka Y, DiFiglia M, Grantz H, Saper CB, Schwartz ML, Leckman JF, Vaccarino FM (2005) Altered parvalbumin-positive neuron distribution in basal ganglia of individuals with Tourette syndrome. Proc Natl Acad Sci USA 102: 13307-13312. CrossRef Medline

Kataoka Y, Kalanithi PS, Grantz H, Schwartz ML, Saper C, Leckman JF, Vaccarino FM (2010) Decreased number of parvalbumin and cholinergic interneurons in the striatum of individuals with Tourette syndrome. J Comp Neur 518:277-291. CrossRef Medline

Kelley JJ, Roberts RC (2004) Effects of haloperidol on cholinergic striatal interneurons: relationship to oral dyskinesias. J Neural Trans 111:1075-1091. CrossRef Medline

Lennington JB, Coppola G, Kataoka-Sasaki Y, Fernandez TV, Palejev D, Li Y, Huttner A, Pletikos M, Sestan N, Leckman JF, Vaccarino FM (2016) Transcriptome analysis of the human striatum in Tourette syndrome. Biol Psychiatry 79:372-382. CrossRef Medline

Li JZ, Vawter MP, Walsh DM, Tomita H, Evans SJ, Choudary PV, Lopez JF, Avelar A, Shokoohi V, Chung T, Mesarwi O, Jones EG, Watson SJ, Akil H, Bunney WE Jr, Myers RM (2004) Systematic changes in gene expression in postmortem human brains associated with tissue $\mathrm{pH}$ and terminal medical conditions. Hum Mol Genet 13:609-616. CrossRef Medline

Logan J, Fowler JS, Volkow ND, Wang GJ, Ding YS, Alexoff DL (1996) Distribution volume ratios without blood sampling from graphical analysis of PET data. J Cereb Blood Flow Metab 16: 834-840. CrossRef

Mahadik SP, Laev H, Korenovsky A, Karpiak SE (1988) Haloperidol alters rat CNS cholinergic system: enzymatic and morphological analyses. Biol Psychiatr 24:199-217. Medline

Martos YV, Braz BY, Beccaria JP, Murer MG, Belforte JE (2017) Compulsive social behavior emerges after selective ablation of striatal cholinergic interneurons. J Neurosci 37:2849-2858. CrossRef Medline

Niederhofer H (2006) Donepezil also effective in the treatment of Tourette's syndrome? Mov Disord 21:2017. CrossRef

Parent M, Bedard MA, Aliaga A, Soucy JP, Landry St-Pierre E, Cyr M, Kostikov A, Schirrmacher E, Massarweh G, Rosa-Neto P (2012) PET imaging of cholinergic deficits in rats using [18F]fluoroethoxybenzovesamicol ([18F]FEOBV). Neuroimage 62:555-561. CrossRef Medline

Parent MJ, Cyr M, Aliaga A, Kostikov A, Schirrmacher E, Soucy J-P, Mechawar N, Rosa-Neto P, Bedard M-A (2013) Concordance between in vivo and postmortem measurements of cholinergic denervation in rats using PET with $\left[{ }^{18} \mathrm{~F}\right] \mathrm{FEOBV}$ and choline acetyltransferase immunochemistry. Eur J Nuc Med Mol Imag Res 3:70. CrossRef

Pedata F, Sorbi S, Pepeu G (1980) Choline high-affinity uptake and metabolism and choline acetyltransferase activity in the striatum of 
rats chronically treated with neuroleptics. J Neurochem 35:606611. Medline

Petrou M, Frey KA, Kilbourn MR, Scott PJ, Raffel DM, Bohnen NI, Müller ML, Albin RL, Koeppe RA (2014) In vivo imaging of human cholinergic nerve terminals with (-)-5-(18)F-fluoroethoxybenzovesamicol: biodistribution, dosimetry, and tracer kinetic analyses. J Nucl Med 55:396-404. CrossRef Medline

Rapanelli M, Frick LR, Xu M, Groman SM, Jindachomthong K, Tamamaki N, Tanahira C, Taylor JR, Pittenger C (2017) Targeted interneuron depletion in the dorsal striatum produces autism-like behavioral abnormalities in male but not female mice. Biol Psych 82:194-203. CrossRef

Robertson MM (2012) The Gilles de la Tourette syndrome: the current status. Arch Dis Child Educ Pract Ed 97:166-175. CrossRef Medline

Shao X, Hockley BG, Tluczek LJM, Hoareau R, Scott PJH (2011) Highlighting the versatility of the tracerlab synthesis modules. Part 1: fully automated production of [18F]labelled radiopharmaceuticals using a tracerlab FXFN. J Label Compd Radiopharm 54:292307. CrossRef

Spokes EGS, Koch DJ (1978) Post-mortem stability of dopamine, glutamate decarboxylase, and choline acetyltransferase in the mouse brain under conditions simulating the handling of human autopsy material. J Neurochem 31:381-383. CrossRef

Spokes EGS (1979) An analysis of factors influencing measurements of dopamine, noradrenaline, glutamate decarboxylase, and choline acetylase in human post-mortem tissue. Brain 102:333-346. CrossRef

Terry AV, Hill WD, Parikh V, Waller JL, Evans DR, Mahadik SP (2003) Differential effects of haloperidol, risperidone, and clozapine exposure on cholinergic markers and spatial learning performance in rats. Neuropsychopharmacol 28:300-309. CrossRef

Vickroy TW, Roeske WR, Gehlert DR, Wamsley JK, Yamamura HI (1985) Quantitative light microscopic autoradiography of $[3 \mathrm{H}]$ hemicholinium-3 binding sites in the rat central nervous system: a novel biochemical marker for mapping the distribution of cholinergic nerve terminals. Brain Res 329:368-373. CrossRef

Yin $\mathrm{HH}$, Knowlton BJ (2006) The role of the basal ganglia in habit formation. Nat Rev Neurosci 7:464-476. CrossRef Medline

Xu M, Kobets A, Du JC, Lennington J, Li L, Banasr M, Duman RS, Vaccarino FM, DiLeone RJ, Pittenger C (2015) Targeted ablation of cholinergic interneurons in the dorsolateral striatum produces behavioral manifestations of Tourette syndrome. Proc Natl Acad Sci USA 112:893-898. CrossRef Medline 